\title{
ANALISIS PENENTUAN BIAYA PELAYANAN PASIEN RAWAT INAP PADA PUSKESMAS PALENGAAN PAMEKASAN
}

\author{
Aminatus Zakhra \\ Zakhra1982@gmail.com \\ Khusairi \\ Khusairi3konom@gmail.com \\ Nailah Aka Kusuma \\ Universitas Islam Madura
}

\begin{abstract}
This study aims to determine the cost of inpatient services at Palengaan Pamekasan Community Health Center. The data analysis method used in this study uses descriptive quantitative analysis. Based on the results of the study indicate that the determination of the cost of inpatient service using the Activity Based Costing method for VIP class inpatient services costs Rp. 160,230.36, - the current tariff is Rp. 150,000, - including the difference of $R p$. 10,230.36, - and in Zaal's class $R p$. 92,868.85, - registration of the current tariff of Rp. 75,000, - including the difference of Rp. 17,868.85, - and the conclusions in using the Activity Based Costing method show that the results are higher than the current rates.
\end{abstract}

Key Words: Activity Based Costing, Cost Determination Analysis, Stay Rate.

\begin{abstract}
ABSTRAK
Penelitian ini bertujuan untuk mengetahui penentuan biaya pelayanan pasien rawat inap Puskesmas Palengaan Pamekasan. Metode analisis data yang di gunakan dalam penelitian ini menggunakan Analisis kuantitatif deskriptif. Berdasarkan hasil penelitian menunjukkan bahwa penentuan biaya pelayanan pasien rawat inap dengan menggunakan metode Activity Based Costing biaya pelayanan pasien rawat inap kelas VIP sebesar Rp. 160.230,36,- penerapan tarif saat ini sebesar Rp. 150.000,- terdapat selisih sebesar Rp. 10.230,36,- dan pada kelas Zaal Rp. 92.868,85,- penerapan tarif saat ini Rp. 75.000,terdapat selisih Rp. 17.868,85,- dan kesimpulannya dalam menggunakan metode Activity Based Costing menunjukkan bahwa hasil yang diperoleh lebih tinggi di bandingkan dengan tarif yang berlaku saat ini.

Kata Kunci : Activity Based Costing, Analisis Penentuan Biaya, tarif inap.

\section{PENDAHULUAN}

Kesehatan merupakan hak asasi setiap orang sehingga di butuhkan entitas pelayanan kesehatan yang baik salah satu upaya pemerintah dalam memenuhi hak warga negara untuk mendapatkan derajat kesehatan yang optimal adalah dibangunkan pelayanan kesehatan berupa puskesmas, baik diperkotaan maupun dipedesaan. Puskesmas merupakan unit pelayanan terdepan maka dari itu dituntut untuk memberikan pelayanan kesehatan yang lebih optimal sehingga mencapai derajat kesehatan. Setelah terjadi krisis ekonomi tahun 1997 beban pembiayaan semakin mahal dikarenakan inflasi yang sangat tinggi hal ini menambah beban biaya kesehatan yang berasal dari pemerintah sehingga perlu rasionalisasi tarif puskesmas sangat diperlukan agar supaya subsidi oleh pemerintah tepat sasaran, dimana sarana kesehatan seperti puskesmas tarif ini biasanya ditetapkan melalui suatu peraturan pemerintah yakni dalam bentuk surat keputusan atau peraturan daerah. Hal ini adanya kontrol ketat dari pemerintah sebagai pemilik sarana pelayanan kesehatan tersebut, akan tetapi disadari bahwa tarif pemerintah biasanya mempunyai cost recovery yang rendah.
\end{abstract}


Penentuan didalam memberikan jasa pelayanan, Puskesmas memporeleh penghasilan dari pendapatan jasa pelayanan dan fasilitas yang diberikan, salah satunya retribusi rawat inap, yang didapat dari tarif yang dibayar oleh pengguna jasa rawat inap. Untuk menentukan tarif Pusksemas diperlukan informasi biaya yang sistematis dan komparatif serta analisis biaya. Misalnya penyuluhan, pemeriksaan medis, pemeriksaan komponen kebugaran jasmani, dan sebagainya. Agar dapat menghasilkan jasa tersebut, maka di perlukan sejumlah input. Input tersebut ada yang langsung digunakan dan dirasakan oleh klien. Misalnya tenaga medis, alat kesehatan, obat-obatan dan sebagainya, dan ada yang tidak langsung digunakan oleh klien, tetapi sangat dibutuhkan demi kelancaran pelayanan misalnya : gedung, alat tulis kantor, alat medis, listrik, air, jejaringan pelayanan kesehatan. Sharon Gondodipuro (2007),

Informasi ini membantu pemerintah daerah untuk menetapkan tarif/retribusi Puskesmas, serta mengevaluasi keefektifan rencanan, mengungkapkan keberhasilan atau kegagalan dalam bentuk tanggung jawab yang spesifik untuk perbaikan dengan adanya berbagai macam fasilitas pada jasa rawat inap, serta jumlah biaya-biaya bahan baku dan biaya lain yang tidak tercantum dalam anggaran rutin, maka perlu ditinjau kembali ketetapan dalam pembebanan biaya yang sesungguhnya, sehingga dalam menentukan biaya pelayanan Puskesmas Palengaan Pamekasan, pemerintah daerah seharusnya memperhatikan biaya-biaya yang seharusnya terbebankan pada pelanggan jasa. Mengingat keanekaragaman pelayanan yang dimanfaatkan pelanggan puskesmas, maka Pemerintah daerah dalam menentukan tarif perlu membandingkan metode akuntansi biaya tradisional dengan mentode activity based costing yaitu penentuan biaya berdasarkan aktivitas. Berdasarkan latar belakang yang telah dikemukakan di atas, maka penelitian diberikan judul: "ANALISIS PENENTUAN BIAYA PELAYANAN PASIEN RAWAT INAP PADA PUSKESMAS PALENGAAN PAMEKASAN. Rumusan Masalah nya adalah Bagaimana penentuan biaya pelayanan pasien rawat inap, serta tujuannya adalah untuk menganalisis penentuan biaya pelayanan pasien rawat inap pada Puskesmas Palengaan Pamekasan

\section{LANDASAN TEORITIS}

Setiaji (2008),"Analisis Biaya Pelayanan Rawat Inap Di Ruang VIP Cendrawasih RSUD DR. Soeselo Kabupaten Tegal" Hasil analisis dengan metode Real Cost di ruang VIP Cendrawasih sebesar Rp 795.790. 311. Miranti (2015),"Analisis Penentuan Tarif Rawat Inap Dengan Metode Activity Based Costing Pada RSUD Hapsari Medika Kota Lubuk Linggau". Hasil perhitungan tarif jasa rawat inap dengan menggunakan metode tersebut,untuk kelas VIP sebesar Rp. 424.087,47, kelas I sebesar Rp. 162.400,93, kelas II sebesar Rp. 135.450,07, kelas III sebesar Rp. 134.436,18.

\section{Akuntansi Biaya}

Menurut Mulyadi (2015:7), Akuntansi biaya adalah proses pencatatan, pengolongan, peringkasan dan penyajian biaya, pembuataan dan penjualan produk atau jasa, dengan cara-cara tertentu, serta penafsiran terhadapnya.

Carter (2009:11) Akuntansi biaya yaitu mengenai pengumpulan, penyajian dan analisis informasi mengenai biaya dan manfaat membantu manajemen untuk menyajikan tugas-tugas berikut:

1. Membantu dan melaksanakan rencana dan anggaran untuk beroperasi dalam kondisi kompetetif dan ekonomi yang telah diperbaiki sebelumnya.

2. Menetapkan metode perhitungan biaya yang memungkinkan pengendalian aktivitas, mengurangi biaya, dan memperbaiki kualitas. 
3. Mengendalikan kualitas fisik dari persediaan, dan menentukan biaya dari setiap produk dan jasa yang dihasilkan untuk tujuan penetapan harga dan untuk evaluasi kinerja dari suatu produk, departemen, atau devisi

\section{Biaya}

Menurut Hansen dan Mowen (2009:47), Mendefinisikan:Biaya adalah kas atau nilai setara kas yang dikorbankan untuk mendapatkan barang atau jasa yang diharapkan akan memberi manfaat saat ini atau di masa depan bagi organisasi.

Menurut Mulyadi (2015:8), Mendefinisikan biaya dalam arti luas, yaitu:Biaya adalah pengorbanan sumber ekonomi, yang di ukur dengan nilai satuan uang, yang telah terjadi atau yang kemungkinan akan terjadi untuk tujuan tertentu.

\section{Klasifikasi Biaya} cara, yaitu

Menurut Mulyadi (2015:13-16), biaya dapat digolongkan dengan berbagai macam Biaya dapat digolongkan menurut:

1. Objek pengeluaran

2. Fungsi pokok dalam perusahaan

Biaya dapat dikelompokkan menjadi tiga kelompok yang terdiri dari:

a. Biaya produksi

b. Biaya pemasaran

c. Biaya administrasi dan umum.

3. Hubungan biaya dengan sesuatu yang dibiayai

Sesuatu yang dibiayai dapat berupa produk atau departemen. Dalam hubungannya dengan sesuatu yang dibiayai, biaya dapat dikelompokkan menjadi dua golongan:

a. Biaya langsung (direct cost)

b. Biaya tidak langsung (indirect cost)

Dalam hubungannya dengan berubahan volume aktivitas, biaya dapat digolongkan menjadi empat yang terdiri dari:

a. Biaya variabel

Biaya variabel adalah biaya yang jumlahnya totalnya berubah sebanding dengan perubahan kegiatan.

b. Biaya semi variabel

Biaya semi variabel adalah biaya yang berubah tidak sebanding dengan perubahan volume kegiatan.

c. Biaya semifixed

Biaya semifixed adalah biaya yang tetap untuk tingkat volume kegiatan tertentu dan berubah dengan jumlah yang konstan pada volume produksi tertentu.

d. Biaya tetap

Biaya tetap adalah biaya yang jumlah totalnya tetap dalam kisar volume kegiatan tertentu.

\section{Komponen Biaya}

Menurut Mulyadi (2015:197-319), komponen biaya, yaitu:

1. Biaya bahan baku

2. Biaya tenaga kerja

3. Biaya overhead pabrik

Biaya-biaya produksi yang termasuk dalam biaya overhead prabrik dikelompokkan menjadi beberapa golongan berikut ini:

a. Biaya bahan penolong 
b. Biaya reparasi dan pemeliharaan

c. Biaya tenaga kerja tidak langsung

d. Biaya yang timbul sebagai akibat penilaian terhadap aktiva tetap

e. Biaya yang timbul sebagai akibat berlalunya waktu

f. Biaya overhead pabrik lain yang secara langsung memerlukan pengeluaran uang tunai

\section{Penentuan Biaya}

Menurut Mulyadi (2015:17), metode penentuan Cost produk adalah cara memperhitung unsur-unsur biaya kedalam Cost produksi. Dalam memperhitung unsurunsur biaya kedalam Cost produksi, dibagi menjadi:

a. Full Costing

Cost produksi menurut metode Full Costing terdiri dari unsur biaya produksi sebagai berikut:

Biaya bahan baku XX

Biaya tenaga kerja langsung $\mathrm{XX}$

Biaya overhead pabrik variabel $\mathrm{XX}$

Biaya overhead pabrik $\quad \underline{\mathrm{XX}}$

Cost produksi $\mathrm{XX}$

b. Variabel Costing

Cost produksi menurut metode Variabel Costing terdiri dari unsur biaya produksi sebagai berikut:

Biaya bahan baku XX

Biaya tenaga kerja langsung $\mathrm{XX}$

Biaya overhead pabrik variabel XX

Cost produksi

\section{Sistem Biaya Tradisonal}

Akuntansi biaya konvensional dibagi menjadi dua tipe: (1) akuntansi biaya dengan fokus ke perhitungan cost produk dan (2) akuntansi pertanggung jawaban Mulyadi (2007:100). Langkah-langkah penentuan harga pokok dengan metode akuntansi biaya konvensional harga pokok dengan system konvensional ditentukan dalam dua tahap Menurut Henry Simamora ( 2005:109), sebagai berikut:

1) Tahap pertama, penelusuran biaya departemen. Biaya bahan baku dan biaya tenaga kerja dibebankan secara langsung ke masing-masing produk.

2) Tahap kedua Biaya overhead dibebankan ke produk sesuai tarif overhead yang dihitung dengan cara total cost overhead dibagi dengan basis tertentu, jam mesin, jam tenaga kerja, biaya tenaga kerja langsung, dan sebagainya.

Sedangkan overhead yang dibebankan $=$ tarif overhead $\mathrm{x}$ unit cost driver yang digunakan dalam metode konvensional.

\section{Sistem Pembebanan Biaya Overhead Pada Activity Based Costing}

Menurut Warindrani (2006:27) tedapat dua pembebanan biaya overhead dengan metode Activity Based Costing yaitu:

1. Biaya Overhead dibebankan pada aktivitas-aktivitas dalam tahapan ini diperlukan 5 (lima) yang dilakukan yaitu:

a. Mengidentifikasi aktivitas.

b. Menentukan biaya yang terkait dengan masing-masing aktivitas.

c. Mengelompok aktivitas yang sejenis menjadi satu.

Pemisahan kelompok aktivitas diidentifikasikan sebagai berikut: 
1. Aktivitas level unit (unit level activities)

2. Aktivitas level produk (product level activities)

d. Aktivitas level fasilitas (facility sutaining activities)

e. Menghitung tarif kelompok aktivitas (homogen cost pool rate).

Untuk menentukan cost driver dihitung dengan rumus:

\section{Tarif Unit Cost Driver $=\underline{\text { Jumlah aktivitas }}$ Cost Driver}

2. Membebankan biaya aktivitas pada produk.

\section{BOP dibebankan $=$ tarif kelompok $\mathrm{X}$ jumlah konsumsi tiap produk}

\section{Pengertian Pelayanan}

Menurut Moenir (2005:47), beliau menjelaskan bahawa pelayanan ialah sebuah proses dari pemenuhan kebutuhan melalui aktivitas orang lain secara langsung. Namun menurut Kotler (2003:464), pelayanan (service) ialah sebagai suatu tindakan ataupun kinerja yang bisa diberikan pada orang lain. Pelayanan atau juga lebih dikenal dengan service bisa di klasifikasikan menjadi yaitu.

1. High contant service ialah sebuah klasifikasi dari sebuah pelayanan jasa dimana kontak diantara konsumen dan juga penyedia jasa yang sangatlah tinggi, konsumen selalu terlibat di dalam sebuah proses dari layanan tersebut.

2. Low contact service ialah klasifikasi pelayanan jasa dimana kontak diantara konsumen dengan sebuah penyedia jasa tidaklah terlalu tinggi.

\section{Kualitas Pelayanan}

Menurut Kotler (2016:3), pelayanan merupakan semua tindakan atau kegiatan yang dapat ditawarkan oleh suatu pihak kepada pihak lain, pada dasarnya tidak berwujud dan tidak mengakibatkan kepemilikan apapun.

\section{METODE PENELITIAN}

Jenis penelitian yang di gunakan adalah penelitian kuantitatif deskriptif. Penelitian ini di laksanakan pada Puskesmas Palengaan Pamekasan.

Waktu penelitian ini dilaksanakan pada bulan maret 2018 sampai selesai.

\section{Sumber Data}

Sumber data yang digunakan dalam penelitian ini adalah data sekunder.

\section{Metode Pengumpulan Data}

1. Dokumentasi

2. Studi kepustakaan.

\section{Jenis Penelitian}

Jenis penelitian yang di gunakan adalah penelitian kuantitatif deskriptif,. Penelitian ini di laksanakan pada Puskesmas Palengaan Pamekasan. Waktu penelitian ini dilaksanakan pada bulan maret 2018 sampai selesai.

\section{Metode analisis Data}

1. Metode full Costing,

2. Metode variabel Costing,

3. Metode tradisional

4. Activity based costing, 
Penggunaan penentuan biaya dengan menggunakan sistem activity based costing dengan melalui dua tahap, yaitu:

1. Tahap pertama

Mendokumentasikan data-data tentang daftar tarif rawat inap yang digunakan oleh pihak Puskesmas Palenggaan Pamekasan.

2. Tahap kedua

Menghitung biaya rawat inap dengan cara mengumpulkan cost pool yang memiliki aktivitas yang sejenis atau homogen, terdiri dari 5 langkah:

a. Mengidentifikasi dan menggolongkan biaya kedalam berbagai aktivitas

b. Mengklasifikasikan aktivitas biaya

c. Mengidentifikasi cost driver

d. Mengidentifikasikan tarif cost driverUntuk menentukan tarif per unit cost driver dihitung dengan rumus:

\section{Tarif Unit Cost Driver $=\underline{\text { Jumlah aktivitas }}$}

Cost Driver

e. Penelusuran dan membedakan biaya aktivitas ke masing-masing produk yang menggunakan cost driver pembebanan biaya overhead dari setiap aktivitas dihitung dengan rumus sebagai berikut:

BOP yang dibebankan $=$ tarif/unit cost driver $\mathbf{x}$ cost driver yang dipilih .

\section{PEMBAHASAN}

Tabel 1

Penghitungan Tarif Jasa Rawat Inap Kelas VIP

Puskesmas Palengaan Pamekasan Tahun 2017

\begin{tabular}{|c|l|l|l|l|}
\hline No & \multicolumn{1}{|c|}{ Aktivitas } & Tarif Cost Driver & \multicolumn{1}{|c|}{ Driver } & \multicolumn{1}{|c|}{ Total } \\
\hline 1 & Biaya jasa perawat & $14.896,81$ & 109 & Rp. 1.623.752,29 \\
\hline 2 & Biaya listrik & $2.571,24$ & 1.964 & Rp. 5.049.915,36 \\
\hline 3 & Biaya air & $750 ., 46$ & 109 & Rp. 81.800,14 \\
\hline 4 & Biaya kebersihan & $5.703,56$ & 109 & Rp. 621.688,04 \\
\hline 5 & Biaya adminisrtasi & $30.431,10$ & 59 & Rp. 3.316.989,9 \\
\hline 6 & Biaya bahan habis pakai & $20.262,66$ & 109 & Rp. 2.208.629,94 \\
\hline 7 & Biaya loundry & $1.400,87$ & 109 & Rp. 152.694,83 \\
\hline 8 & Biaya depresiasi gedung & 750.000 & 4 & Rp. 3.000.000 \\
\hline 9 & Biaya depresiasi fasilitas & $9.005,62$ & 109 & Rp. 981.067,58 \\
\hline \multicolumn{2}{|l|}{ Total Biaya Untuk Kelas VIP } & & Rp. 17.036.538 \\
\hline Jumlah Hari Pasien Rawat Inap & & & Rp. 156.298,51 \\
\hline Tarif Jasa Rawat Inap Per Hari & & & \\
\hline
\end{tabular}

Sumber Data: data diolah tahun 2017 


\section{Tabel 2}

Penghitungan Tarif Jasa Rawat Inap Kelas Zaal

Puskesmas Palengaan Pamekasan Tahun 2017

\begin{tabular}{|c|l|l|l|l|}
\hline No & \multicolumn{1}{|c|}{ Aktivitas } & Tarif Cost Driver & \multicolumn{1}{|c|}{ Driver } & \multicolumn{1}{|c|}{ Total } \\
\hline 1 & Biaya jasa perawat & $14.896,81$ & 1.490 & Rp. 22.196.246,9 \\
\hline 2 & Biaya listrik & $2.571,24$ & 2.703 & Rp. 6.960.061,72 \\
\hline 3 & Biaya air & $750 ., 46$ & 1.490 & Rp. 1.118.185,4 \\
\hline 4 & Biaya kebersihan & $5.703,56$ & 1.490 & Rp. 8.498.304 \\
\hline 5 & Biaya adminisrtasi & $30.431,10$ & 1.490 & Rp. 45.342.339 \\
\hline 6 & Biaya bahan habis pakai & $20.262,66$ & 1.490 & Rp. 30.191.361,4 \\
\hline 7 & Biaya loundry & $1.400,87$ & 1.490 & Rp. 2.087.296,3 \\
\hline 8 & Biaya depresiasi gedung & 750.000 & 12 & Rp. 9.000.000 \\
\hline 9 & Biaya depresiasi fasilitas & $9.005,62$ & 1.490 & Rp. 13.418.373,8 \\
\hline \multicolumn{2}{|l|}{ Total Biaya Untuk Kelas Zaal } & & Rp. 138.803.171 \\
\hline Jumlah Hari Pasien Rawat Inap & & & Rp. 93.516,49 \\
\hline \multicolumn{2}{|l|}{ Tarif Jasa Rawat Inap Per Hari } & & \\
\hline
\end{tabular}

Sumber Data: data diolah tahun 2017

Dari perhitungan di atas tabel 1 dan 2, dapat diketahui bahwa hasil perhitungan tarif jasa rawat inap dengan menggunakan metode Activity Based Costing untuk kelas VIP Rp. 156.298,51,- kelas Zaal Rp. 93.156,49,-. Dari hasil tersebut, jika di bandingkan dengan tarif yang erlaku saat ini kelas VIP Rp. 150.000,kelas Zaal Rp. 75.000 maka Activity Based Costing memberikan hasil yang lebih besar sehingga terdapat selisih untuk kelas VIP Rp.6.298,51,- Atau 4,0\% dari tarif yang ditentukan kelas Zaal Rp. 18.156,49,- Atau 19,49\% dari tarif yang ditentukan. Untuk lebih jalasnya, dapat di lihat tabel berikut:

Tabel 3

Perbandingan Tarif Jasa Rawat Inap Puskesmas Palengaan Pamekasan dan Metode Activity Based Costing Tahun 2017

\begin{tabular}{|l|c|c|c|l|}
\hline Tipe kamar & Tarif puskesmas & Tarif ABC & Selisih & $\begin{array}{l}\text { Selisih } \\
\text { Persen \% }\end{array}$ \\
\hline Kelas VIP & Rp. 150.000 & Rp.160.230,36 & Rp.6.298,51 & $4,0 \%$ \\
\hline
\end{tabular}




\begin{tabular}{|l|c|c|c|c|}
\hline Kelas Zaal & Rp. 75.000 & Rp. 92.868,85 & Rp.18.156,49 & 19,49\% \\
\hline
\end{tabular}

Table 4

Penghitungan Tarif Jasa Rawat Inap Kelas Zaal

Puskesmas Palengaan Pamekasan Tahun 2017

\begin{tabular}{|c|l|l|l|l|}
\hline No & \multicolumn{1}{|c|}{ Aktivitas } & Tarif Cost Driver & \multicolumn{1}{|c|}{ Driver } & \multicolumn{1}{|c|}{ Total } \\
\hline 1 & Biaya jasa perawat & $14.896,81$ & 1.490 & Rp. 22.196.246,9 \\
\hline 2 & Biaya listrik & $2.571,24$ & 2.703 & Rp. 6.960.061,72 \\
\hline 3 & Biaya air & $750 ., 46$ & 1.490 & Rp. 1.118.185,4 \\
\hline 4 & Biaya kebersihan & $5.703,56$ & 1.490 & Rp. 8.498.304 \\
\hline 5 & Biaya adminisrtasi & $30.431,10$ & 1.490 & Rp. 45.342.339 \\
\hline 6 & Biaya bahan habis pakai & $20.262,66$ & 1.490 & Rp. 30.191.361,4 \\
\hline 7 & Biaya loundry & $1.400,87$ & 1.490 & Rp. 2.087.296,3 \\
\hline 8 & Biaya depresiasi gedung & 750.000 & 12 & Rp. 9.000.000 \\
\hline 9 & Biaya depresiasi fasilitas & $9.005,62$ & 1.490 & Rp. 13.418.373,8 \\
\hline \multicolumn{2}{|l|}{ Total Biaya Untuk Kelas Zaal } & & Rp. 138.803.171 \\
\hline \multicolumn{2}{|l}{ Jumlah Hari Pasien Rawat Inap } & & Rp. 93.516,49 \\
\hline \multicolumn{2}{|l|}{ Tarif Jasa Rawat Inap Per Hari }
\end{tabular}

Sumber Data: data diolah tahun 2017

Dari perhitungan di atas tabel diatas dapat diketahui bahwa hasil perhitungan tarif jasa rawat inap dengan menggunakan metode Activity Based Costing untuk kelas VIP Rp. 156.298,51,- kelas Zaal Rp. 93.156,49,-. Dari hasil tersebut, jika di bandingkan dengan tarif yang berlaku saat ini kelas VIP Rp. 150.000,kelas Zaal Rp. 75.000 maka Activity Based Costing memberikan hasil yang lebih besar sehingga terdapat selisih untuk kelas VIP Rp.6.298,51,- Atau 4,0\% dari tarif yang ditentukan kelas Zaal Rp. 18.156,49,- Atau 19,49\% dari tarif yang ditentukan. Untuk lebih jalasnya, dapat di lihat tabel berikut:

Tabel 5

Perbandingan Tarif Jasa Rawat Inap Puskesmas Palengaan Pamekasan dan Metode Activity Based Costing Tahun 2017

\begin{tabular}{|l|c|c|c|l|}
\hline Tipe kamar & Tarif puskesmas & Tarif ABC & Selisih & $\begin{array}{l}\text { Selisih } \\
\text { Persen \% }\end{array}$ \\
\hline Kelas VIP & Rp. 150.000 & Rp.160.230,36 & Rp.6.298,51 & 4,0 \\
\hline Kelas Zaal & Rp. 75.000 & Rp. 92.868,85 & Rp.18.156,49 & 19,49 \\
\hline
\end{tabular}


Berdasarkan tabel 5 di atas setelah di lakukan perhitungan dengan metode activity based costing menunjuk hasil yang lebih tinggi di bandingan dengan tarif yang berlaku di Puskesmas Palengaan.

\section{PENUTUP}

\section{Kesimpulan}

Berdasarkan pembahasan pada bab IV mengenai tarif rawat inap pada Puskesmas Palengaan Pamekasan. dapat di ambil kesimpulan sebagai berikut:

1. Harga beradasarkan perhitungan yang telah dilakukan dapat di ketahui bahwa biaya rawat inap untuk pasien pada Puskesmas Palengaan Pamekasan berbeda pada setiap kelasnya, sesuai dengan pelayanan yang di berikan oleh Puskesmas Palengaan Pamekasan

2. Harga berdasarkan perhitungan dengan metode Activity Based Costing di banding dengan harga yang ditentukan oleh Puskesmas Palengaan berdasarkan peraturan daerah kabupaten Pamekasan No. 15 Tahun 2015, tanggal 13 Maret 2012 adalah sebagai berikut:

a. Kelas VIP

Harga berdasarkan perhitungan metode Activity Based Costing adalah Rp. 156.298,51,- sedangkan harga yang berlaku Puskesmas Palengaan Rp. 150.000,sehingga terdapat selisih harga Rp.6.298,36,-. Atau 4,0\% dari tarif yang ditentukan

b. Kelas Zaal

Harga berdasarkan perhitungan metode Activity Based Costing adalah Rp. 93.156,49,- sedangkan harga yang berlaku Puskesmas Palengaan Rp. 75.000, sehingga terdapat selisih harga Rp.18.156,49,-. Atau 19,49\% dari tarif yang ditentukan.

\section{Rekomendasi Atau Saran}

Sebaiknya tarif yang berlaku pada Puskesmas Palengaan Kabupaten Pamekasan sebaiknya melakukan pertimbangan kembali atas tarif rawat inap dengan menggunakan metode activity based costing, karena dapat di ketahui biaya yang sesungguhnya. Hal tersebut di karenakan metode activity based costing merupakan perhitungan yang tepat dan akurat dengan pembebanan aktivitas pada masing-masing kamar rawat inap. Perhitungan yang di hasilkan metode activity based costing. Menyajikan data yang sesungguhnya, sehingga penentuan tarif dan estimasi laba yang di peroleh dapat lebih tepat.

\section{DAFTAR PUSTAKA}

Carter. K William. 2009. Akuntansi Biaya. Buku 1. Edisi Keempat belas. Jakarta: Penerbit Selemba Empat.

Gondodipuro, Sharon, 2007. Penghitungan Unit Cost Dipelayanan Kesehatan Primer, IKM Universitas Pajajran Bandung

Hansen dan Mowen. 2009. Manajeral Akunting. Edisi 8. Jakarta: Penerbit Selemba Empat. Henry Simamora. 2005. Manajemen Sumber Daya Manusia. Jakarta: PT Bumi Aksara 
Kotler, Philip. 2016. Prinsip - Prinsip Pemasaran Manajemen . Jakarta. Prenhalindo

Kotler.2003. Marketing Manajemen. Edisi 11. Jakarta: PT. Indeks Kelompok Gramedia

Miranti. Bunga Miranti. 2015. Analisis Penentuan Tarif Rawat Inap Dengan Metode Activity Based Costing Pada RSUD Hapsari Mediaka Kota Lubuklinggau. Skripsi-S1 STIE Mura Lubuklinggau

Mulyadi. 2003. Activity Based Costing Sistem Informasi Biaya Untuk Pengurangan Biaya, Edisi 6. Penerbit Yogyakarta UPP APM YKPN.

Mulyadi. 2015. Akuntansi Biaya. Edisi 5. Cetakan Ketigabelas. Penerbit Sekolah Tinggi Ilmu Manajemen YKPN.

Moenir, H.A.S. 2000. Manajemen Pelayanan Umum di Indonesia. Jakarta: Bumi Aksara

Setiaji. Hendadi. 2008. Analisis Biaya Pelayanan Rawat Inap Di Ruang VIP Cendrawasih RSUD DR. Soeselo Kabupaten Tegal.

Warindrani, Amilia krisna. 2006. Akuntansi Manajemen. Yogyakarta: Penerbit Grahalu 